Article

\title{
The Research on Temporal-Spatial Distribution and Morphological Characteristics of Ancient Settlements in the Songhua River Basin
}

\author{
Meng Zhu ${ }^{1,2}$, Jianfei Dong ${ }^{2, *}$ and Yingzhi Gao ${ }^{2, *}$ \\ 1 School of architecture, Harbin institute of technology, Harbin 150001, China; zhumeng064@163.com \\ 2 Heilongjiang Cold Region Architectural Science Key Laboratory, Harbin 150006, China \\ * Correspondence: 17S034064@stu.hit.edu.cn (M.Z.); g86289227g@163.com (Y.G.)
}

Received: 4 January 2019; Accepted: 5 February 2019; Published: 12 February 2019

check for updates

\begin{abstract}
Settlements have a high cultural and historical value in regions as indicators of human habitation and culture. The Songhua River Basin is on the edge of a traditional cultural center, which has scattered ecological elements, a special culture, and historical faults. Because of the superposition of traces of different ethnic activities in different periods, the Songhua River has a special and diversified cultural foundation and heritage, which is of high research value. However, the ancient settlements in this region have not been given sufficient attention and as a result it is difficult to achieve a complete and systematic study. In order to promote the cultural value of this historical region and the development of a regional and cultural industry, this paper seeks to study the ancient settlements of Songhua River Basin. With the help of GIS technology, archeological excavations, and the concept of ethnic pedigree in ethnology, this study analyzes the temporal-spatial distribution and morphological characteristics of ancient settlements in the Songhua River Basin, in order to determine how the heritage value of these settlements can be sustainably protected.
\end{abstract}

Keywords: ancient settlements; Songhua River Basin; temporal-spatial distribution; morphological characteristics

\section{Introduction}

The Sustainable Development Goals (SDG) were proposed at the United Nations Sustainable Development summit held in New York in 2015. The goals aim to solve the developmental problems in the three dimensions of society, economy and environment and to turn to the path of sustainable development, among which the Sustainable Cities and Communities goal is very important for regional development. Under the impact of modern civilization, the regional protection of cultural heritage has been given more attention by various countries. The excavation of 19 cultural geographic spaces and the construction of cultural ecological protection areas have been carried out in different degrees. Therefore, the study on the development of settlements in the region is of great significance for the sustainable development of the region [1-3]. This topic has been deeply considered in the planning of sustainable development and the traditional culture of cultural heritage conservation Since 19 Century [2,4]. In Europe, the United States, and other countries, sustainable development is mainly manifested through the establishment of ecological museums, cultural routes and cultural heritage areas, In China, the research on ancient settlements is mostly concentrated in the area of traditional architectural culture, while the research on settlements in marginal areas still needs to be improved. In particular, research on the temporal-spatial distribution and morphological characteristics of ancient settlements in the Songhua River Basin is still an unexplored area in the study of architectural history.

Northeast China has always been a special geographical location in Chinese history, and the ancient nations of northeast China have played a very important role in the formation and development 
of Chinese culture. From a macro perspective, the history and culture of the Songhua River Basin, and even the Aumer Basin, are of the same value as the Yangtze River and the Yellow River, which are considered the cradles of Chinese civilization [5,6]. The long-term contact, collision, and fusion between the minority system and the Huaxia Family can be traced back to the Shang-Zhou period. Later, the Xianbei (鲜卑), Khitan (契丹), Nuzhen (女真), Mongolian (蒙古族), Manchu (满族), and other ethnic groups became the dominant groups in the north and even occupied the central plains, which promoted the integration of the north and the south many times in Chinese history, and even changed the pattern of the whole east Asia region [7]. The research on the settlements in northeast China can be traced back to the colonization study led by Russia and Japan in the middle of the last century. At present, representative settlements in the Songhua River Basin have been excavated, such as the Fenglin (凤林) ancient city in the Sanjiang Plain from the Han-Wei period and the capital city of the Bohai States during the Tang Dynasty [8-10]. However, studies of ancient settlements in the Songhua River Basin are based on archaeology, and therefore mostly descriptive and qualitative. Furthermore, the methods used are only based on discovery records, historical data, and research from the site; there is no in-depth study on the temporal-spatial distribution and morphological characteristics of the settlement. The object of this study is the ancient settlements in the Songhua River Basin (Figure 1). Learned from the west since the 19 century in the traditional culture of cultural heritage protection methods, and with the help of GIS (Geographic Information System) spatial analysis technology, we analyzed the temporal-spatial distribution and morphological characteristics of ancient settlements in the Songhua River Basin, and accuracy the ancient cultural heritage sites. This is the basis for the planning of cultural and ecological protection areas, so as to put forward planning content from the perspective of inheritance and development in the future. This will help to realize the sustainable development demands of regional heritage protection, urban construction, and economic development.

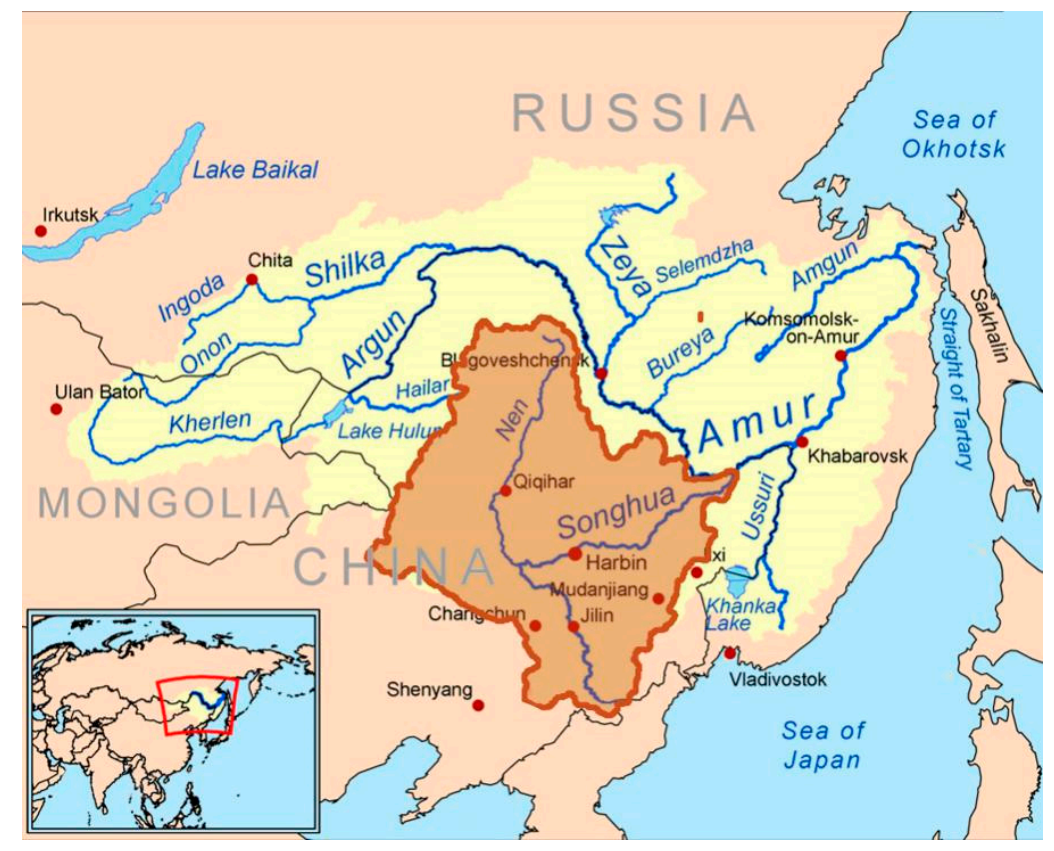

Figure 1. Schematic diagram of the Songhua River Basin.

\section{Methods}

The research methods of ancient settlements are no longer based on a single subject knowledge, but permeate each other. Nowadays, with the development of related disciplines, the emergence of new technologies [11] such as Hadoop, and GIS, there are new technical means for the research and analysis of ancient settlement sites. Furthermore, interdisciplinary research methods from the perspectives of archaeology [12], cultural geography [13], and ethnic culturology [14] provide new ideas and 
perspectives for the analysis of temporal-spatial distribution and the morphological characteristics of ancient settlements. Based on the results of archaeological excavations, and with the help of GIS technology, this study analyzed the temporal-spatial distribution and morphological characteristics of ancient settlements in the Songhua River Basin.

GIS means geography information analysis system, and is a tool for understanding geographical location and analyzing environmental information based on a database [15]. In order to establish a settlement spatial database, a large amount of graphic data, historical data, location data, and other resources were collected and sorted in the early stages. The system integrates and stores data, and provides an information management platform for spatial analysis. GIS is a visual management platform based on existing information, and has been applied in archaeology, soil and water resources research, and other fields. In recent years, due to its convenience in data collection and management, as well as its visual output, it has been widely used in the field of architecture, especially in regional planning and history research $[16,17]$.

By extracting key words such as heritage city, ancient city, mountain city, town site, city site, settlement site, ancient castle, border castle, fortress, village, stronghold, and so on in the State Administration of Cultural Heritage [18-20] and the National Cultural Heritage Administration [21-23], the author obtained more than 2000 ancient settlements. Located in Heilongjiang, Jilin, and the Inner Mongolia provinces, these settlements were used as research objects for the temporal-spatial distribution and morphological characteristics of ancient settlements. Based on the statistics of ancient settlements information, the GIS database of temporal-spatial distribution of ancient settlements in the Songhua River Basin was constructed to realize the visual expression and quantitative analysis of the development of ancient settlements, so as to directly show their development process and regional distribution characteristics.

\section{Analysis}

\subsection{Temporal-Spatial Distribution of Settlements}

The ancient settlement database of the Songhua River Basin established by GIS directly reflects the distribution of settlements in various time periods. In this way, the distribution pattern and temporal-spatial evolution of ancient settlements in the Songhua River Basin during each period on the time line can be visualized, which facilitates the logical analysis and quantitative expression of the temporal-spatial evolution of ancient settlements (Table 1).

Table 1. The number of ancient settlements in each period and the visual expression of ArcGIS.

\begin{tabular}{|c|c|c|c|c|c|}
\hline Period & Shang-Zhou & Han-Wei & Tang-Bohai & Liao-Jin & Ming-Qing \\
\hline $\begin{array}{l}\text { The number of } \\
\text { settlements }\end{array}$ & 19 & 531 & 143 & 611 & 40 \\
\hline \multicolumn{6}{|l|}{$\begin{array}{l}\text { Visualization based } \\
\text { on GIS }\end{array}$} \\
\hline $\begin{array}{l}\text { The number of sites } \\
\qquad\left(\geq 50,000 \mathrm{~m}^{2}\right)\end{array}$ & 290 & 69 & 26 & 230 & 40 \\
\hline $\begin{array}{l}\text { Visualization based } \\
\text { on GIS }\end{array}$ & & & & & \\
\hline
\end{tabular}


Generally speaking, the Songhua River Basin in the late Paleolithic period was marked by a large area of human activities, and in the Shang-Zhou period had settlement construction activities. Examples include the south city site of Yufeng (渔丰) in Raohe (饶河) county, Wupaishan (五排山) city site in Dongning (东宁) county, and Liangtai (粮台) mountain city site in the city of Muling (穆棱). Although the number of settlements found and confirmed make it difficult to form a system, it is enough to prove that the ancient settlements in the Songhua River Basin were in the embryonic stage of settlement development during the Shang-Zhou period. The Han dynasty began to record large-scale construction activities during the Han-Wei period, and a concentrated distribution of ancient settlements appeared in the Songhua River Basin. After a certain period of fault, a large number of settlements were built in the later Tang-Bohai period. The Liao-Jin period experienced another peak of settlement development after the Yuan dynasty completed the unification of the northeast region, and the urban settlement in the region was basically formed in the Ming-Qing period. At this time, there were few large-scale construction activities, and the morphological changes were weak compared with those before, which was in the declining period of the ancient settlement morphological development in the Songhua River Basin.

The kernel density of settlements in different periods were calculated. The higher the value, the darker the color, which indicates the existence of a large-scale centralized distribution of settlements in this region during this period. After calculating the kernel density of the ancient settlements in each period, we concluded that the settlements in the three periods of Han-Wei, Tang-Bohai, and Liao-Jin were distributed on a large scale. In particular, the Han dynasty appeared to have massive construction activity, the centralized distribution of ancient settlements first appeared in the Han-Wei period. In the GIS kernel density analysis, the density of settlements in the area between the Songhua River, Aumer River, and Wusuli (乌苏里) River increased significantly. Most of these settlements were concentrated around Xingkai (兴凯) Lake, Muling River, Naoliv (挠力) River, and other water systems, and the spatial distribution showed that the organic form was dominated by the native culture (Figure 2).
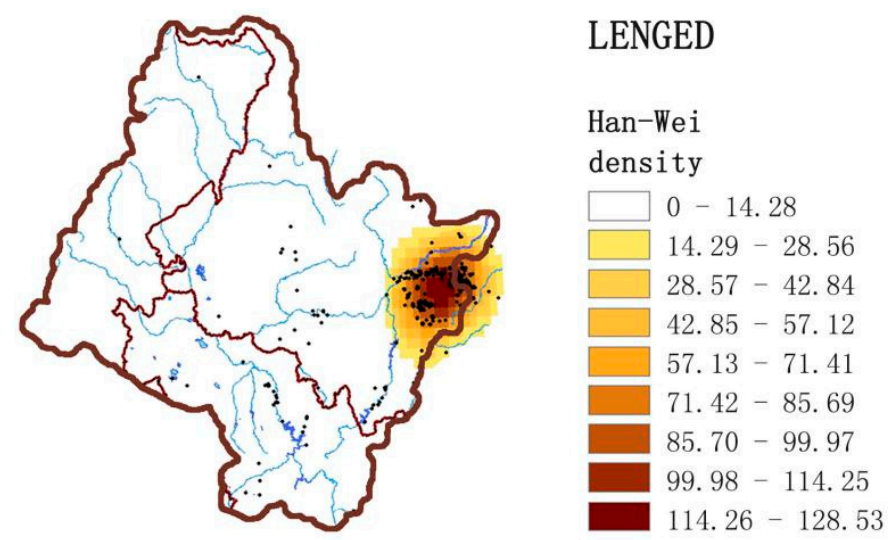

Figure 2. The kernel density of ancient settlements during the Han-Wei period.

Due to wars and frequent changes of dynasties, the development of ancient settlements in the Songhua River Basin showed a certain period of fracture after the Han-Wei period. The Tang-Bohai period ushered in the development of the second peak (Figure 3). The settlements of Bohai States were mainly distributed in the Mudan River Basin, the largest tributary on the right bank of the Songhua River. At this time, the spatial distribution of the settlements showed that major cities were surrounded by satellite cities, which reflected the migration and infiltration of the Tang dynasty culture. 


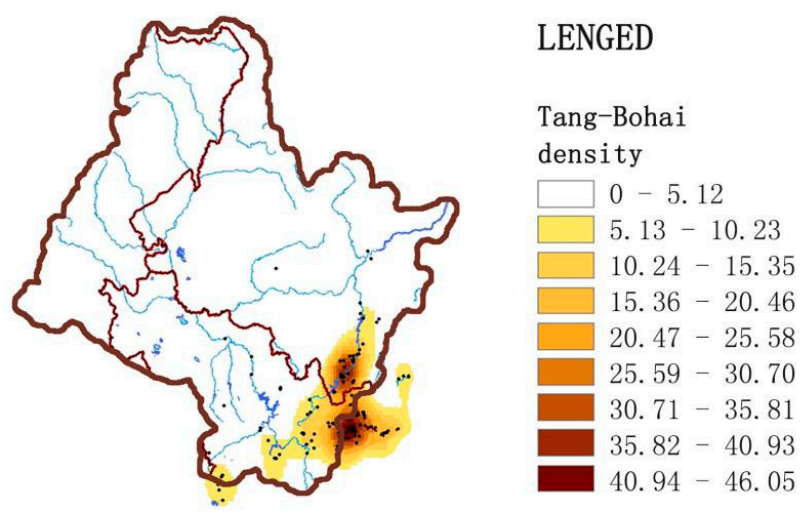

Figure 3. The kernel density of ancient settlements during the Tang-Bohai period.

The Liao-Jin period was the third peak of settlement development (Figure 4). It was also the highest peak of the development of all the ancient settlements. The Liao, Jin, and Yuan dynasties built a large number of settlements in the rule of northeast China for more than 400 years. These settlements were mostly distributed along the main rivers and the plain areas washed out by the rivers, especially in the Songnen Plain, the largest plain area in the basin.
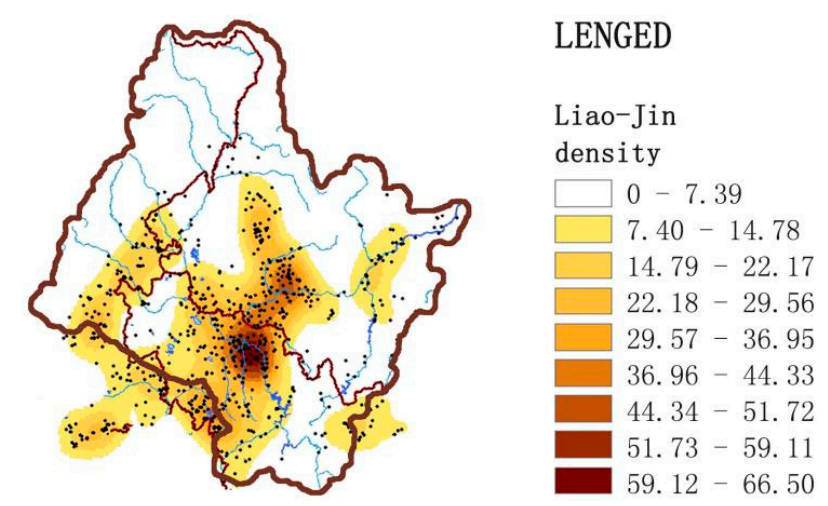

Figure 4. The kernel density of ancient settlements during the Liao-Jin period.

\subsection{Settlements Dominated by Different Cultural Forms}

In the process of historical development, the frequent collision and integration of different ethnic groups made the ethnic composition system of the Songhua River Basin very complex. This study is divided into three categories: farming culture, fishing and hunting culture, and nomadic culture, according to the dominant cultural forms of ethnic groups, so as to avoid controversial issues on ethnic groups and genera in settlement analysis. In this study, the logical relationship between settlement site selection and dominant cultural form was explored by analyzing the altitude, topography, hydrology, and other geographical environment information of settlements in different periods in the GIS and combining the dominant cultural form of settlements [24,25].

Figures 5-8 display the elevation calculation of settlement points in the Han-Wei period and the aspect, slope direction, and buffer zone calculation of urban site points. Under the dominance of a fishing and hunting culture, the distribution of ancient settlements in the Han and Wei dynasties were mostly concentrated in the Sanjiang Plain, which had a large number of water systems, complex topography, dense forests, and abundant resources of wetlands and hilly regions between mountains and rivers. During this period, Sushen (肃慎), Yilou (挹娄), Wuji (勿吉), and other ethnic groups with fishing and hunting as their main production methods chose this settlement site to adapt to the characteristics of a hunting and gathering community. The social structure of this period was mainly organized as a clan commune with blood relationship as the bond. Therefore, the overall layout of its settlements was not restricted by the obvious etiquette system and order, which was mainly 
manifested as the original organization form based on production and life, and dominated by natural geographical conditions.

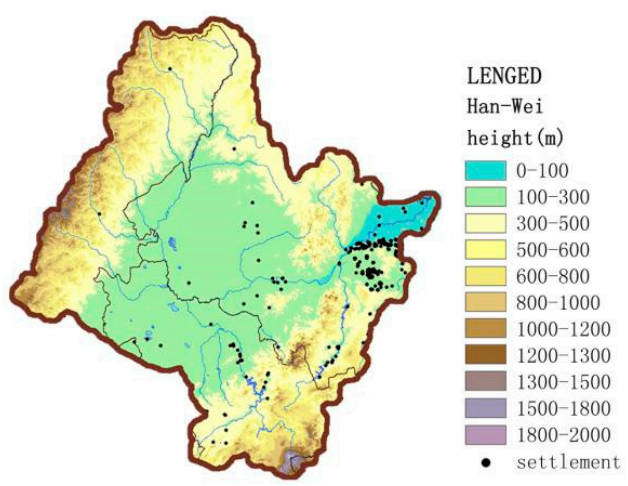

Figure 5. Elevation of the Han-Wei period.

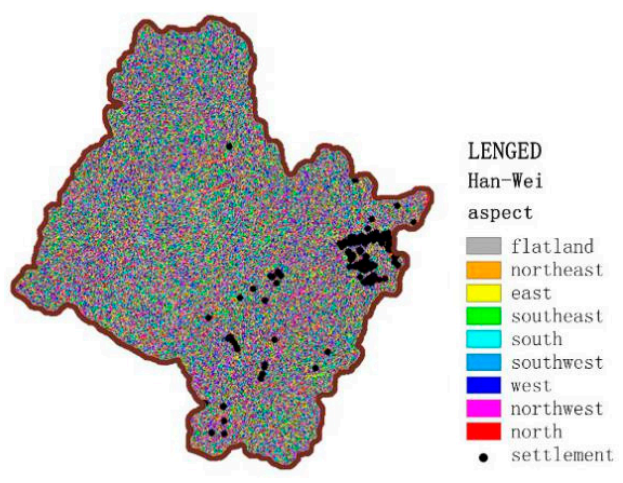

Figure 6. Aspect of the Han-Wei period.

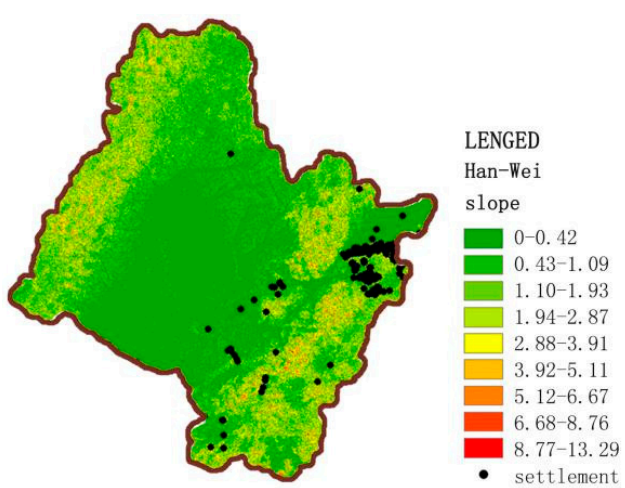

Figure 7. Slope of the Han-Wei period.

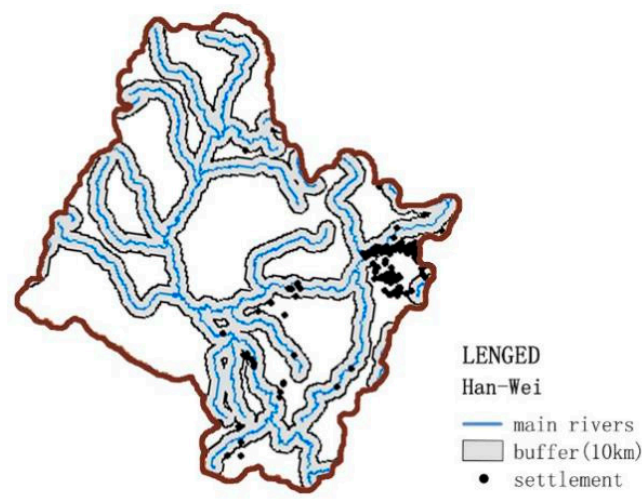

Figure 8. Buffer of the Han-Wei period. 
Based on the analysis of settlements in the Tang-Bohai period (Figures 9-12), it can be seen that the distribution of settlements in the Songhua River Basin was mainly concentrated in the Mudan River valley hills and gentle mountains. The Bohai States were a political power established by the Mohe branch and supported by the Tang Dynasty. These States covered a vast area but the main settlements were concentrated in the present-day border between China and Korea. Mohe nationality's early production mode was mainly hunting, but its political power was supported by the Tang dynasty, so it was deeply influenced by Han culture. Although the current archaeological findings show that in the period of the Bohai States, there were more mountain cities and fewer plain cities, most sites with a dominant status and high administrative level were in the plain. The mountain cities were mainly built on the main road on both sides of the Mudan River, and played a defensive role by controlling the pass. In this period, the layout of urban sites or the choice of form and system did not matter; ancient settlements showed a high degree of imitation and absorption of Han culture and ritual in the central plains, with a trend from irregularity to regularity.

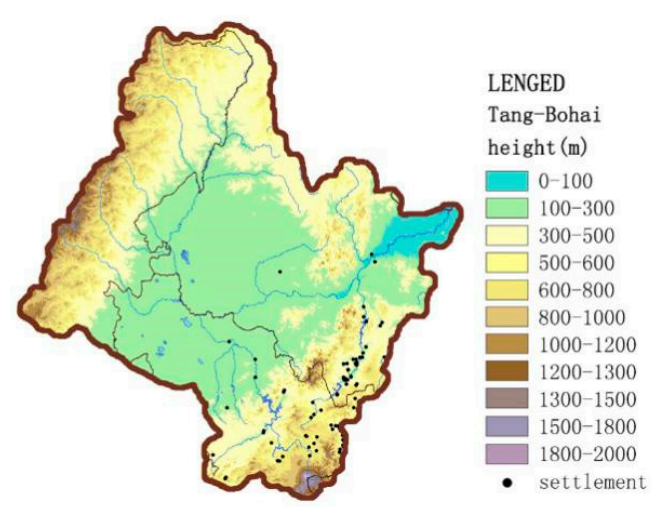

Figure 9. Elevation of the Tang-Bohai period.
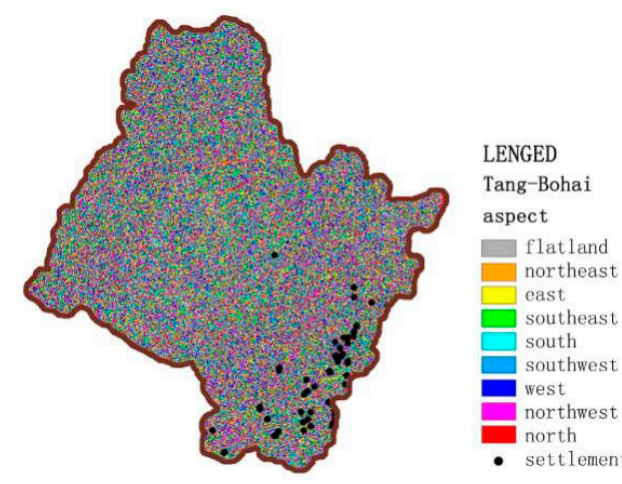

Figure 10. Aspect of the Tang-Bohai period.

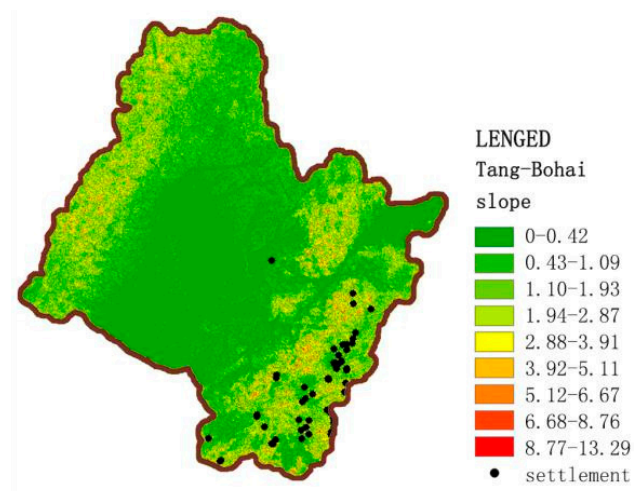

Figure 11. Slope of the Tang-Bohai period. 


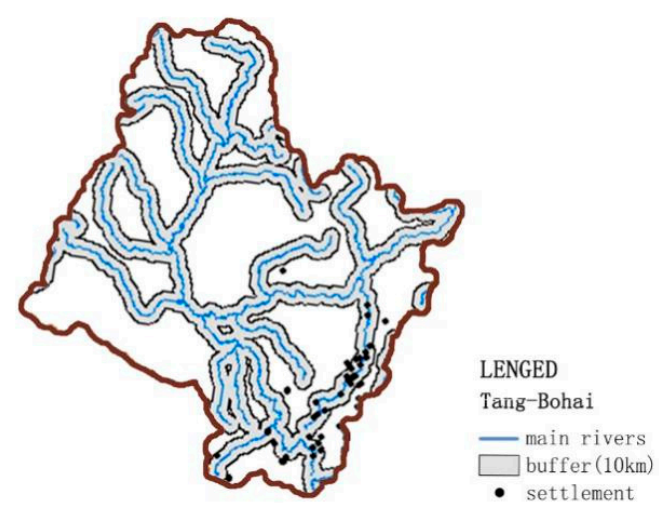

Figure 12. Buffer of the Tang-Bohai period.

During the Liao-Jin period, the dominant national ideology is nomadic culture, and a large number of settlements were selected in plain areas with a flat and open terrain, such as the Songnen Plain, which was washed out by the confluence of the Songhua River and Nen River (Figures 13-16). The Liao-Jin period did not inherit the same form as the Tang-Bohai period, where the urban sites were mostly built in the direction of the river's course, with vision and abundant water and grass. Such site selection was in line with the production mode of nomadic people. Later, the rise of the Nuzhen and Mongolian ethnic groups forced a large number of Han people to move to the Songnen Plain, which brought advanced agricultural technology and brought about a large-scale reclamation of the Songhua River Basin. Through the integration of the farming culture of the central plains and the nomadic culture of the northern region, the ancient settlements in the Songhua River Basin reached an unprecedented state of prosperity. In addition, in order to strengthen their rule and resist the invasion of foreign nations, a large number of settlements integrated their military and political agendas to build border forts and walled forts in dangerous terrain, such as the highlands and slopes, during the Liao-Jin period.

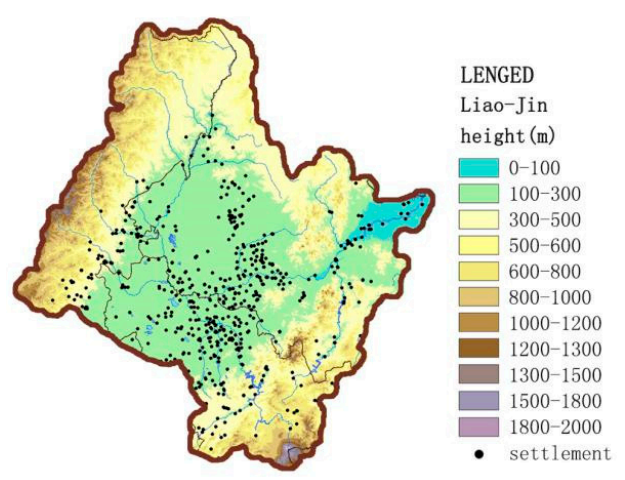

Figure 13. Elevation of the Liao-Jin period.

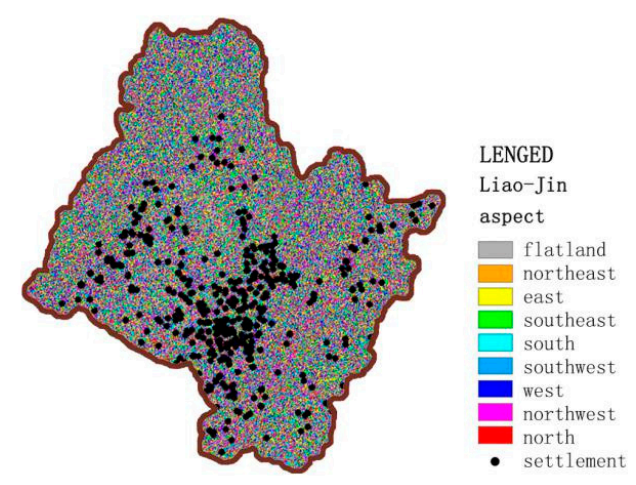

Figure 14. Aspect of the Liao-Jin period. 


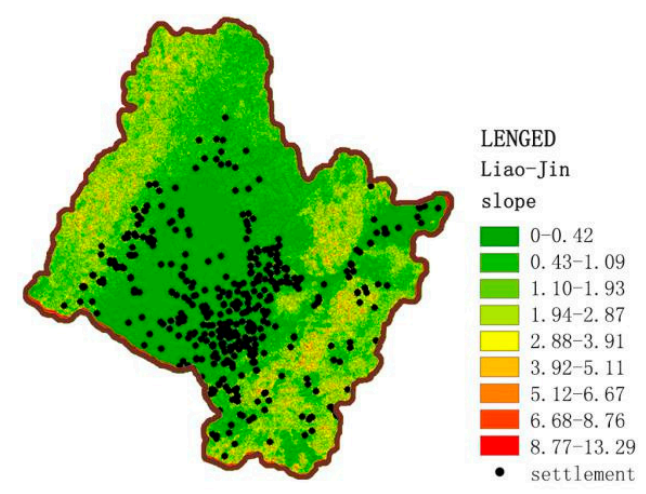

Figure 15. Slope of the Liao-Jin period.

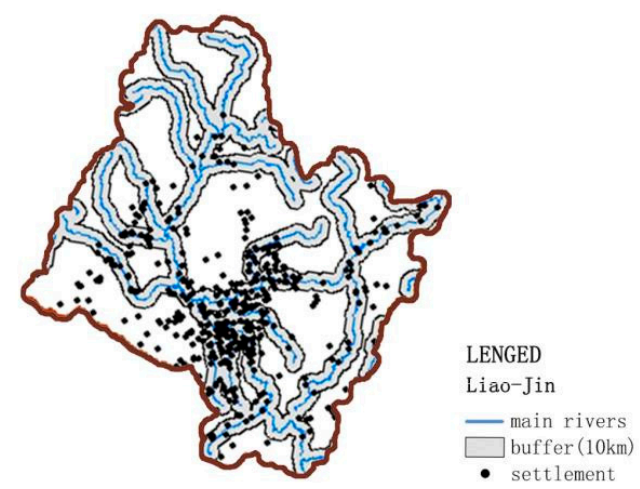

Figure 16. Buffer of the Liao-Jin period.

\section{Results and Discussion}

Ascan be seen from the analysis above, the fishing and hunting ethnic groups in the Han-Wei period ushered in the first climax of the development of settlements in the Sanjiang Plain. After a period of fracture, the establishment of the Bohai States ushered in the second climax of settlement development in the West Songhua River. During the Liao-Jin period, large-scale settlements were built on the vast plain formed by confluence of the Songhua River, West Songhua River, and Nen River (Figure 17). Due to the complicated ethnic composition, frequent wars, and the harsh natural environment of the Songhua River Basin, the temporal-spatial distribution of ancient settlements in the Songhua River Basin lagged behind that of the central plain. Under the influence of many factors such as different politics and cultural ideologies, each period presented the characteristics of weak continuity at the time level, regional differences at the space level, and discontinuous transition in development.

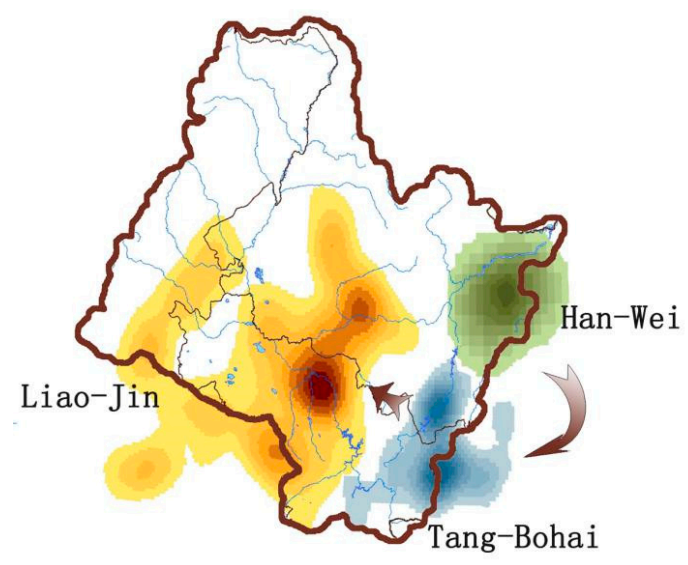

Figure 17. Schematic diagram of settlement development direction in each period. 
The elevation, slope, slope direction, and buffer zone of ancient settlements in these three periods were statistically analyzed in GIS. Settlement locations in different periods were all selected in the range below $300 \mathrm{~m}$ in elevation, and the upward slope aspect of site selection in different periods was mainly a sunny slope. Even in the case of a northwest direction, the slope was gentle and similar to the geographical location of a flat slope, which reflected the limitation factors of the natural environment and production mode for settlement selection. In terms of slope selection, the settlements in different periods were rarely located on steep slopes (Figure 18). During the Han-Wei and Tang-Bohai periods, when hunting and gathering were the main modes of production, the settlements were distributed in large proportions in the plains, hills, and small undulating mountains. However, in the Liao-Jin period, because nomadic culture was the dominant cultural form, the tendency to settle on gentle terrain was more obvious. Most of the urban sites were located in the alluvial and diluvial plain at a low elevation, even though the few urban sites at the edge of the terrain were usually militarily and politically integrated settlements.

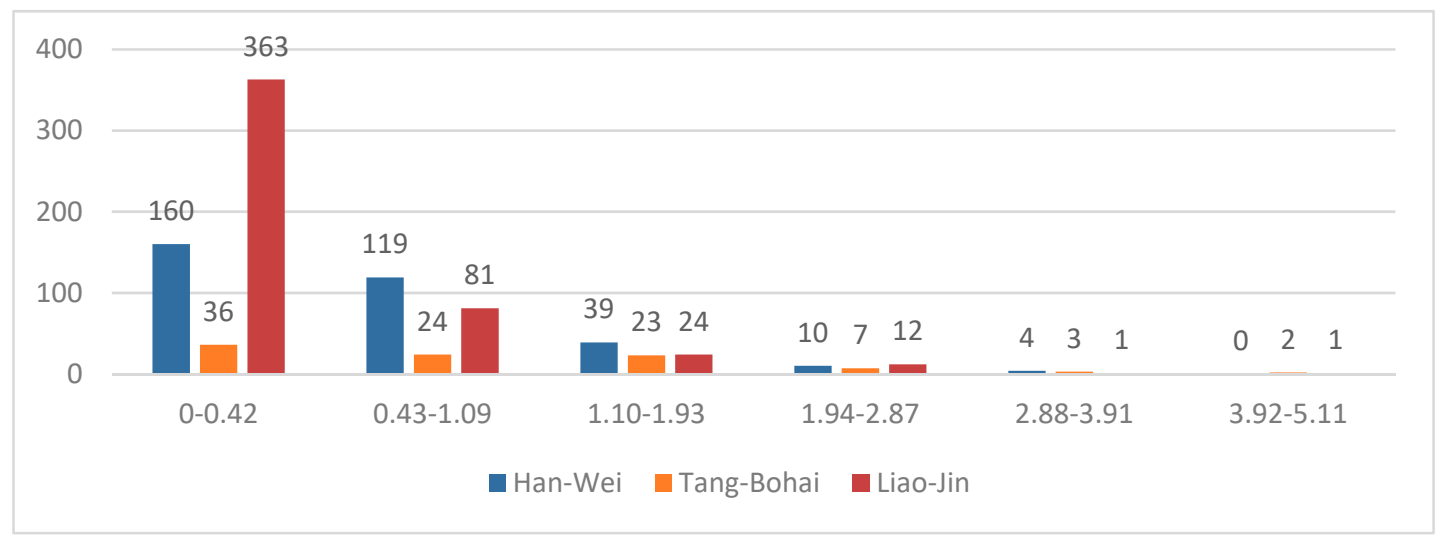

Figure 18. Aspect statistics of settlements in different periods.

The analysis of a main river buffer of $10 \mathrm{~km}$ shows (Figure 19) that settlements dominated by a nomadic culture had a great demand for a relatively stable water system, and that urban sites were mostly close to the large open main water system around the basin. Settlements with only collection and farming as production methods were mostly located in the hilly regions with abundant resources and near the small tributaries of the alluvial plain.

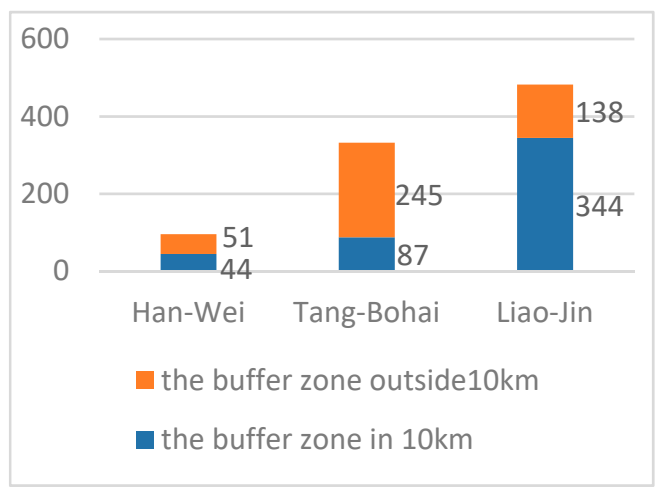

Figure 19. Buffer statistics.

\section{Conclusions}

In this study, the GIS database of ancient settlement sites in the Songhua River Basin was constructed, and a temporal-spatial distribution dynamic superposition map was drawn to visualize the historical distribution information of ancient settlements in this region. The map helped to construct 
the historical context of settlement development in northeast China and to some extent improve the perception of the development of ancient Chinese traditional settlements. The temporal-spatial distribution rules of ancient settlements in the Songhua River Basin were sorted out by Big Data Analysis, which indicated that the development of ancient settlements in the Songhua River Basin experienced peaks of settlement construction formed by different cultural groups during the three periods of Han-Wei, Tang-Bohai, and Liao-Jin. This shows that the development of ancient settlements in the Songhua River Basin was very different from the development of the center region of Han culture, with weak continuity at the time level, regional differences at the space level, as well as evolution rules and characteristics of nontemporal transitional development. The ancient history and culture of the Songhua River Basin has formed its own unique geographical history and cultural system through the settlement and migration, confrontation and inclusion, absorption and exclusion of different cultural traditions, and the ancient settlements in this area appeared in various forms. Therefore, as a marginal area of Han culture, the ancient settlements in the Songhua River Basin formed a complex development system with multiple threads interlaced, integrating openness, closure, and inclusiveness.

In addition, GIS was used in this study to rationally study the development process of a certain region and analyze its temporal-spatial distribution and morphological characteristics. This is not only a supplement to archaeological information, but also a perfection of the research framework of historical heritage, thus enhancing the protection and utilization of regional cultural heritage. This study examined the regional cultural heritage of the Songhua River Basin and constructed a multidimensional geographic information database of the ancient settlements in the Songhua River Basin in terms of time process and spatial form. It can also be used as a basis for future research, using GIS and other quantitative analysis tools, drawing lessons from the foreign, cultural, and ecological protection area planning scientific methods, as well as from the perspective of inheritance and development of regional planning, to achieve the Sustainable Development Goals of regional heritage protection, urban construction, and economic development.

Author Contributions: Conceptualization, J.D.; methodology, J.D.; software, M.Z.; validation, Y.G. and J.D.; formal analysis, investigation, M.Z.; resources, J.D.; data curation, M.Z.; writing—original draft preparation, M.Z.; writing-review and editing, J.D.; visualization, M.Z.; supervision, Y.G.; project administration, J.D.; funding acquisition, Y.G.

Funding: This research was funded by "NSFC 51408166" and "NSFC 51878203".

Conflicts of Interest: The funders had no role in the design of the study; in the collection, analyses, or interpretation of data; in the writing of the manuscript, or in the decision to publish the results.

\section{References}

1. Long, D. The Research of Foreign Cultural Ecology Preservation Area Planning. Master Thesis, Southeast University, Nanjing, China, 2016.

2. Yang, J.Q. Protection of urban and rural cultural heritage based on cultural ecology and complex system. Urban Plan. Forum 2016, 40, 103-109.

3. Yu, Y.; Lu, Y.D. Study on traditional settlements in southeast China-The framework of human settlements. Huazhong Architect. 1996, 4, 42-47.

4. Lucchi, E. Review of preventive conservation in museum buildings. J. Cult. Herit. 2017, 29, $180-193$. [CrossRef]

5. Wu, W.Y.; Zhang, T.X.; Wei, G.Z. Brief History of Heilongjiang Ancient Times; Northern Cultural Relics: Heilongjiang, China, 1987; pp. 67-75.

6. Wang, Y.L. Study on the Civilization of the Northeast Basin; Social Sciences Academic Press: Beijing, China, 2016; pp. 42-76.

7. Wang, Y.L. Study on the Historical Geography of Northeast. China from the Perspective of East Asia; Social Sciences Academic Press: Beijing, China, 2016; pp. 91-113.

8. Pan, C.L.; Ai, S.Q. Heilongjiang River Basin Civilization from a Multi-dimensional Perspective; Heilongjiang People's Publishing House: Heilongjiang, China, 2006; pp. 57-69.

9. Wei, C.C. Ancient Ethnic Origins in Northeast China. Chin. Borderl. Hist. Geogr. Stud. 2017, 27, 27-45, 180. 
10. Wang, Y.L. Overview of Ancient Cultural Relics of ancient cities in Northeast China. Heilongjiang Natl. Ser. 1995, 4, 53-64.

11. Zhang, J. Application of GIS technology in settlement archaeology. J. Zhengzhou Univ. 2016, 49, 113-115.

12. Zhang, G.Z.; Hu, H.B.; Zhou, Y.; Chen, X.C. Settlement Patterns in Archaeology. Huaxia Archaeol. 2002, 1, 61-84.

13. Liu, D.P.; Li, X.J. Studies on History of Chinese Architecture and Cultural Geography. Architect. J. 2005, 6, 68-70.

14. Li, J.H. The Cultural Interpretation of Southwest Settlement Patterns. Ph.D. Thesis, Chongqing University, Chongqing, China, 2010.

15. Tang, G.A.; Yang, X. ArcGIS Analysis Experiment Tutorial, 2nd ed.; Science Press: Beijing, China, 2012; pp. 25-165.

16. Zhang, J.W. Chen, W. Hu, M.X. Application and Exploration of GIS Technology in Protection Planning of Large Sites. Architect. J. 2010, 6, 23-27.

17. Yuan, Y. Research on the Construction of Digital City Geospatial Framework Based on GIS. Constr. Des. Eng. 2019, 1, 194, 195, 198.

18. State Administration of Cultural Heritage. Atlas of Chinese Cultural Relics: Heilongjiang Volume; Wenwu Publishing House: Beijing, China, 2015.

19. State Administration of Cultural Heritage. Atlas of Chinese Cultural Relics: Jinlin Volume; China Map Press: Beijing, China, 1993.

20. State Administration of Cultural Heritage. Atlas of Chinese Cultural Relics: Inner Mongolia Volume; Wenwu Publishing House: Beijing, China, 2003.

21. National Cultural Heritage Administration. Catalogue of Chinese Unmovable Cultural Relics: Heilongjiang Volume; Wenwu Publishing House: Beijing, China, 2011.

22. National Cultural Heritage Administration. Catalogue of Chinese Unmovable Cultural Relics: Jinlin Volume; Wenwu Publishing House: Beijing, China, 2011.

23. National Cultural Heritage Administration. Catalogue of Chinese Unmovable Cultural Relics: Inner Mongolia Volume; Wenwu Publishing House: Beijing, China, 2003.

24. Zhang, J.Q. Study on Traditional Settlement in Northeast evolving topography, climatic factors and human factors reaches. Master Thesis, Xi'an University of Architecture and Technology, Xi'an, China, 2016.

25. $\mathrm{Bu}$, X.C. Quantitative Research on the Integrated Form of the Two-dimensional Plan to Traditional Rural Settlement. Ph.D. Thesis, Zhejiang University, Zhejiang, China, 2012. 